\title{
Ethnic identity: peculiarities of interaction between family values and multi-ethnic student environment through the example of Dagestani students
}

Saida Gasanova ${ }^{1 凶}$

This study focused on the issue of ethnic identity of students as a process of interaction between the family upbringing values and multi-ethnic university environment on the example of Daghestani students of Moscow universities. The central study objective was to determine the effect of family values on the formation of national identity in students, as well as to identify whether there are any statistical differences in these terms between males and females. A total study sample included 214 Daghestani students from 15 Moscow universities distributed into two groups: experimental one (composed of Dagestanis) and control (multiethnic group). The research participants were asked to specify their national identity and assess the use of their mother tongue as an identifier. The null hypothesis of this study suggested that there are no significant differences between the assessments of Dagestani males and females towards traditional family values and no significant differences in ethnic identification between students of the experimental and control groups. The groups were compared based on the results of Pearson's chi-squared test and Pearson's correlation coefficient calculation. As a consequence, the null hypothesis was confirmed only for the students of the 4 th and 5 th study years. The practical value of the collected findings resides in their possibility to be used to address psychological problems in multi-ethnic student groups and create optimal conditions for personal development and ethnic identification of students.

\footnotetext{
${ }^{1}$ Peoples' Friendship University of Russia, Moscow, Russian Federation. ${ }^{凶}$ email: Saida_a_a@mail.ru
} 


\section{Introduction}

he process of national identity formation has been studied for a long time, which led to the emergence of different means of ethnicity assessment and measurement (Rath and Schutjens, 2019; Svensson et al., 2018; Verkuyten, 2018). The major focus of ethnology is the subjective identification of an individual with a particular ethnic group (Bamberger, 2020). Many researchers note the complex historical and dynamic nature of identification, assimilation processes, the replacement of monoethnicity with polyethnicity, and the multifactorial nature of the ethnic consciousness development (Svensson et al., 2018; Verkuyten, 2018).

In modern conditions, educational environment and family relations tend to be diversified in terms of both students' ethnicity and race (Fischer et al., 2015; Forrest-Bank and Cuellar, 2018; Poster, 2002). At the same time, the population of the urban landscape around the world is multi-ethnic, and now, the processes of interaction and mixing of ethnic groups are being intensified (Johnston-Guerrero, 2016). However, even though the foregoing, national identity is still an extremely important factor in the development of personality, family culture, educational choices, and behavioral stereotypes in many contexts (JohnstonGuerrero, 2016; Verkuyten, 2018). One of the most common hypotheses of the origin of ethnic self-identification is that national identity is developed at an early age in the process of being brought up in the family and is based on a certain tradition or its elements cultivated as a "tradition representation" (Kusumaningtyas et al., 2019). Thus, family and ethnicity are often identical to a child, even in multi-ethnic families where the cultures of parents of different origins are mixed. Later in life, when basic personality traits are formed, personal national identity is likely to be stable even in spite of the person's self-assessment that may be sharply negative or provoke rejection due to destructive external pressure (racial or national persecution or discrimination) (Maximova and Belyaev, 2017; Mustafaeva et al., 2016a). In parallel, some researchers point that participation in an academic learning environment, especially a multi-ethnic one, and intensive self-education may erode ethnic identity, contributing to the development of a neutral multi-ethnic consciousness (Rath and Schutjens, 2019; Svensson et al., 2018; Thijs, 2017).

The matter of determining one's ethnicity has a gender-linked aspect as well. Researchers state that the difference in the processes and dynamics of self-identification between males and females is reflected mainly in the context of interaction in marriage in multiethnic marriages (Fischer et al., 2015; Kaya et al., 2019). Empirical studies on ethnic identification processes indicate little or no differences between genders in different dimensions of ethnic identification (van der Does and Adem, 2019). In most cases, women are found to be more conservative and more likely to remain committed to ethnic behaviors derived from the family or their ethnic environment (Harel-Shalev et al., 2020; Zimmermann et al., 2007).

The change of identification often occurs due to economic reasons or as a means of social mimicry. A good example of such mimicry can be the historical change of identity by Jewish people in a hostile environment when the danger of death and the high probability of mixing with other peoples led to the inheritance of identification specific to the maternal line (Verkuyten, 2018). Analogical mimicry was demonstrated by Koreans. In the course of persecution by the Japanese authorities, they were often forced to claim that they were Japanese or American mestizos to eliminate identification with a slavery past (Verkuyten, 2018).

The period of the active development of a young person at student age is still the most dynamic in the context of the ethnic identification changes. Many researchers highlight the possibility of shifting and changing identification in connection with higher education and increased intellectual development or new life experience (Rath and Schutjens, 2019; Thijs, 2017). During the study period, family values representing ethnic experience and values actively interact with a multi-ethnic environment, new values, and experience. Their interaction becomes one of the key factors in the ethnic identification of a person throughout their whole life. It can be assumed that the changes most actively affect more flexible and sensitive youth of student age. Communication within the intellectual culture of universities often contributes to the formation of a more universal worldview and influences identification (Fisher et al., 2017; Rath and Schutjens, 2019).

\section{Dagestan case exploration}

Of all the subjects of the Russian Federation, the Republic of Dagestan, located in the North Caucasus, is the most multinational. According to the estimates of various ethnographers and geographers, the number of ethnic groups inhabiting the Republic may exceed 100. Among them, there are numerous representatives of non-local ethnic groups who moved to the Caucasus: Russians, Ukrainians, Russian Germans, Tatars, Armenians, Azerbaijanis, etc. More than 30 ethnic groups are indigenous. Dagestan is also a subject of the Russian Federation, which has the largest Muslim population (about 96\% of the permanent population of the Republic, or more than 3 million people are Muslims; $97 \%$ of them are Sunnis, and 3\% are Shiites). Individual peoples of Dagestan, as a rule, profess the same religion, speak their own language, and are predominantly localized within the framework of individual municipalities into which the territory of Dagestan is divided. The state languages of the Republic incorporate Russian and 14 other local ones that are literary written. Of course, the number of languages used in the region is much larger, but a significant part of them are unwritten and are used only locally within a few mountain communities or areas. The most widely spoken languages are Avar, Dargin, Kumyk, and Lak; they correspond to the most numerous ethnic groups in the region. No less interesting is also the fact that most of the languages belong to the independent local Nakh-Dagestan (they are spoken by more than $75 \%$ of the population of Dagestan), Turkic (20\%), and Indo-European (about 55\%) language groups. In the 19th century and until the middle of the 20th century (Abdulmanapov, 2021; Carment et al., 2006), the role of the common language of interethnic communication in Dagestan (lingua franca) was played by the Kumyk language of the Turkic language group. Its role was consolidated in 1923 when Soviet power was established in the North Caucasus. However over time, the role of this language increasingly blurred, and now it is understandable only to representatives of the Kumyks as an ethnic group that speaks it. Now the function of the lingua franca in the region is performed by Russian (Dobrushina and Kultepina, 2021).

As for other aspects, Dagestan is known for the predomination of the rural population (55.6\%), the surplus of labor, and the problem of employment and earnings. Even though Dagestan has 47 vocational educational institutions and 72 higher educational institutions and their branches, a significant part of the population receives only basic secondary education. The total number of students in Dagestan exceeds 120 thousand. The overwhelming majority of them (over 94\%) are Dagestani and representatives of neighboring regions of the Russian Federation. Only a small part of young Dagestanis has the opportunity to study at Russian universities outside their region (Kamalova et al., 2021).

\section{Literature review}

Many recent studies have begun to consider national identity as part of human or social capital (Bamberger, 2020; Fischer et al., 
2015). This approach can be deemed adequate as belonging to an ethnic group allows a person to participate in the networks of trust that connect group representatives, to demonstrate the advantages of their ethnicity, and to claim certain preferences that are associated with this (Blake, 2019; Forrest-Bank and Cuellar, 2018). In the meantime, in modern conditions, such social and human capital can be implemented only if there is multi-cultural competence, which provides knowledge both about one's own ethnic culture and about the interaction with the representatives of other cultures and their characteristics (Ahmad and Yusof, 2017).

The student environment becomes a place and a means of acquiring multi-cultural competence, a training ground for developing skills to solve real-life problems in the field of social interactions in a multi-ethnic society. The state and its programs directed at ethnic diversity support play an essential role in stimulating this process (Verkuyten, 2018; Zagirova et al., 2018). This type of support is important primarily for recognizing the equivalence of different ethnic groups and races within the framework of common human values and interests of a particular society and a state (Thijs, 2017; Zaman, 2020). The development of a digital environment and opening of a total communicative space contributes to post-national identification and pushes students towards the formation of multi-cultural competence (Kusumaningtyas et al., 2019; Svensson et al., 2018).

Researchers note the special status and dynamics of the processes of ethnic identification among minority ethnic groups (Svensson et al., 2018). As a rule, such groups have certain historically developed and caused by the state policy problems in the socio-economic relations with the representatives of other population segments. In the course of their studies, students belonging to these groups have dramatic differences in behavior (Gummadam et al., 2016). These differences can be traced to the resistance to assimilation, the formation of a neutral multi-ethnic identity, or to dual identification processes (Thomsen and Rafiqi, 2017). The results of the study of these processes indicate that, in many cases, an education level increase leads to the shift of rigid ethnic identification towards multi-ethnicity (Rath and Schutjens, 2019; Thijs, 2017). At the same time, the principles of behavior and values that the individual associates with their national identity may not coincide with their real experience, which belongs to the culture that the individual inhabited in the course of family education (Chikaeva et al., 2019; Clark et al., 2017).

Mustafaev et al. (2016b), examining the peculiarities of the interaction of state policy and local ethnic traditions in Dagestan, note the leading role of state policy in maintaining national identity. They also claim that the formation of national patriotism in the multi-ethnic Russian Federation in the conditions of the coexistence of numerous peoples with a long history of complex relationships is one of the cornerstone tasks of politics. The authors argue that the elimination of conflict in the selfidentification of each nation in the context of multinational communication is closely related to the conduct of a cautious patriotic education.

The dynamic change in ethnic identification in an urban multiethnic student environment is an important subject to study. In modern academic discourse, some aspects of the relationship between traditional family values that determine ethnicity and an urbanized multi-cultural environment in individual countries are paid relatively less attention. Moreover, the links between traditional family education in its ethnically marked aspect and the characteristics of behavior and learning in higher education are addressed more rarely than other aspects of this broad issue. As mentioned above, higher education and an increase in the intellectual status of a person who determines their identity play a dramatic role in this dynamic process.
The purpose of this research was to identify the link between traditional family values and the impact of a multi-ethnic student environment on the student's national identity formation. The research objectives were as follows:

- to determine whether the nature of national identity changes during studies (from the first to the fourth academic year);

- to find out whether there are differences in the nature of ethnic identification and its changes between males and females (through the example of Daghestani students);

- to determine the extent of changes in the assessment and adherence to traditional family values under the influence of multi-ethnic student groups.

Thus, in accordance with the study objectives, two null hypotheses were formed:

1. There are no statistically significant differences between the responses of males and females of Dagestan origin related to national identity and the assessment of their compliance with traditional family values.

2. There is no statistically significant linear relationship between the ethnic identification of students in the experimental (Dagestani) and control (multi-ethnic) groups.

The following two alternative hypotheses must be accepted if null hypotheses were rejected as a result of testing:

1. There are statistically significant differences between the answers of males and females of Dagestan origin related to national identity and the assessment of their compliance with traditional family values.

2. There is a statistically significant linear relationship between the identification of students in the experimental (Dagestani) and control (multi-ethnic) groups.

\section{Methods}

Participants. The study included two groups of 214 students of Dagestan origin from 15 universities of Moscow. The first one consisted of students of Dagestan origin and was experimental, whereas the second was multi-ethnic and was used as a control group. In order to select a random sample and exclude the influence of one particular university, the sample was sorted to include participants from different universities; each university was represented by not more than 17 students. This was done to avoid bias and eliminate possible statistical deviations in the ethnic characteristics of students in each individual university, which could have developed historically, geographically, or for any other reason. In addition, there was an equal proportion of males and females in each of the five academic years examined (Table 1).

A similar group of 214 multi-ethnic students from the same universities (except for Dagestanis) was formed to perform the role of a control group. The experimental group, which was defined here as Dagestanis, was, in fact, multi-ethnic and consisted of representatives of the nationalities inhabiting the Dagestan Republic of the Russian Federation. However, they were gathered into one group for a number of reasons significant for the study:

1. the group was represented by people who identify themselves as Avars (78), Dargins (71), and Kumyks (65); a significant part of them come from mixed marriages between representatives of various indigenous peoples of Dagestan and mixed marriages with Russians in the next two generations (at least $76 \%$ according to researchers' estimates based on the results of personal conversations 


\begin{tabular}{|c|c|c|}
\hline Study year & Males & Females \\
\hline Year 1 & 21 & 21 \\
\hline Year 2 & 22 & 22 \\
\hline Year 3 & 21 & 21 \\
\hline Year 4 & 22 & 21 \\
\hline Year 5 & 21 & 22 \\
\hline Total & 107 & 107 \\
\hline
\end{tabular}

with participants). All members of the group identified themselves as Sunni Muslims;

2. all members of this group perceived themselves as Dagestanis, as a certain cohort, separated from other students by behavioral, linguistic, religious, and ideological characteristics. This separation was facilitated by the fact that their social environment also perceived them as Dagestanis and did not follow a more subtle division into separate nationalities within this conditional population.

As was already noted, taking into account the predominantly multi-ethnic composition of students at Russian universities, the control group turned out to be multi-ethnic. This was further verified by the researchers using a simple additional survey on students' ethnic self-identification. The control group participants represented 27 nationalities and declared to use 18 different languages as their mothers (among them were Russian, Ukrainian, Tatar, German, Chechen, Bashkir, Chuvash, etc.). The obtained data were not presented here in detail because they are redundant; it is only important for the study purposes that the control group was multi-ethnic. The students were selected randomly to ensure that the results were as relevant as possible.

The central research method was the survey, the objectives and features of which were explained clearly. It was administered and completed in Russian, which all participants were fluent in. The students who agreed to participate in the study were selected according to a set of indicators (gender, university course, nationality) to fit the sample requirements. All of them were sent questionnaires by e-mail; the data obtained were statistically processed.

\section{Research design}

The experimental group participants were asked to answer three questions. The first question asked whether they identify themselves as Dagestani and, if yes, to what extent do their behavior and values reflect the idea of the behavior of a Dagestani. The answer was expected to be given on a Likert scale from 0 ("I do not consider myself a Dagestani; my behavior does not correspond to the behavior of a Dagestani") to 5 (I consider myself a Dagestani; my behavior fully reflects the way a Dagestani should behave").

In the second question, using the same five-point Likert scale, respondents were asked to assess the extent to which they share their traditional family values (from 0 - "I do not share them at all" to 5 - "I completely share traditional family values"). Owing to the fact that in the preliminary survey, all the participants noted their native language as a traditional family value, it was decided to evaluate national identity on this basis.

The third question asked the students to assess the frequency of the use of their native language to communicate with relatives and conduct an internal monologue. Their answers corresponded to the following Likert scale points:

0 - "I never use it";
1 - "Sometimes, I predominantly use my second language";

2 - "I use my native language often, but in most cases, I use other languages";

3 - "I use my mother tongue and other languages equally";

4 - "I use my mother tongue more often compared to other languages";

5 - "I always use my mother tongue and never use other languages in such circumstances".

In the first and second questions, the participants themselves had to determine to which of the extreme statements represented by points 0 and 5 they were more inclined and, based on their feelings, indicate a point on the scale. In the third question, it was possible to choose the precise answer for each item.

Data analysis. The three-question survey described above was addressed to both groups of students under examination. However, while in the experimental group, the questions (as indicated in the examples in the Research design section) concerned the Dagestani nationality, in the control group, similar questions were formulated but with the mother tongue and nationality of each student indicated. After that, in both groups, the arithmetic means were calculated for each question and each type of answer based on the Likert scale. In order to determine the statistical significance of differences between the results of the participants of different genders and study years, this study used the Student's $t$-test. Its essence lies in the fact that if the difference between the mean values of the statistically random distribution between the two groups is greater than a certain confidence interval (most often determined at $5 \%$ of all values), then the difference between the tested groups is not random, but obeys different patterns. In this case, we can say that the variations between the two groups are not the result of accidental but a pattern that must be investigated and explained.

To test the hypothesis about the stronger influence of the multi-ethnic environment on the development of students' ethnic self-awareness, the results of the experimental (Dagestani) and control (multi-ethnic) groups in the context of each gender and study year were compared based on the Pearson correlation coefficient. If the correlation between the responses of the two groups turns out to be strong enough, the assumption that the participants in an ethnically defined (experimental) group are susceptible to the influence of the multi-ethnic environment will be proved.

Statistical processing. To process the data obtained during the study and visualize the results, the MS Excel 2019 software was used.

Ethical issues. All participants were guaranteed the anonymity of their participation in the survey. No personal data were processed or collected in the course of the study. Each survey participant received a unique randomly generated identification number and e-mail address to send the completed survey. Thus, the anonymity of the experiment was ensured.

Compliance with ethical requirements was approved by the Institutional Review Board of Peoples Friendship University of Russia by protocol No. 3248 dated 07.24.2020.

Research limitations. First of all, this study was limited by the fact that the impact of the student community cannot be separated from the impact of the living environment as the environment of a large city (in this case, Moscow) is multi-ethnic. Taking into account the study load, the peculiarities of living (mainly in the student dormitory), and the distribution of time, one can assume with a high degree of confidence that the impact 
of the student environment still prevails. Another limitation of this work relates to the sample size as it cannot ensure accurate and statistically significant compliance with the requirements for the adequacy of the sample representativeness. The lack of differentiation of participants not only by the year of study but also by age can be considered one more limitation, but in the current case, the year of study is critically important because it shows the duration of contact with the multi-ethnic environment. The last point to consider in this respect is that the paper fails to address what disciplines the participants studied at the university, although this can be a significant factor influencing ethnic identification. Further studies may pay more attention to this issue to prove or confute this point of view.

\section{Results}

The results of students' national identity self-assessment are described in Figs. 1 and 2. As can be seen, in the experimental group, national identity indicators have slightly changed by the fifth-year of study. The experimental group participants still identify themselves as Dagestanis and are confident that they behave exactly like Dagestanis, whatever that means. The study does not provide a clear definition of behavior in order to fix subjective self-identity that does not contain a critical attitude. As concerns the control group, although precise national identity self-assessment outcomes were recorded for first-years, they significantly blurred by the fifth-year of study. This generally corresponds to the results of some world research works in the area (Gummadam et al., 2016; Kusumaningtyas et al., 2019; van der Does and Adem, 2019).

Among the multi-ethnic students of the first-year of study, $65.12 \%$ could clearly define their national identity, while in the fifth study year, their share was only $14.28 \%$. No less important is also the fact that all first-years identified themselves in accordance with the nationality indicated in their internal national passports, whereas as much as $9.52 \%$ of fifth-years claimed that their ethnic identity was different from the passport one. During the Soviet era, there was a longstanding ambiguity when filling out the "nationality" column in the passports of the multinational population of a huge country. As a result of repressions, many representatives of small nations indicated not their nationality but more widespread one or even Russian in order to get a better job or for numerous other reasons. In parallel, often, the passports even indicated "Dagestani" as nationality, although Dagestan is the historical name of a geographical area that is not associated with any nation that would have such a name. The Soviet government, which declared the goal of creating a "new community of people-the Soviet people," supported the practice of unification. However, even though over the past 20 years this sort of habit has been almost eliminated, old passport entries recording the wrong nationality are often passed on to descendants unchanged. This result is also consistent with the research results indicating that an increase in the level of education blurs national identity.

Figures 3 and 4 show the outcomes of students' assessment of their commitment to family values. As evidenced by their data, experimental group participants are more committed to their family values at the beginning of training than at its end. The number of those who completely or largely do not associate their behavior with traditional family values in the experimental group is minimal and can be assessed as being on the edge of statistical reliability.

In contrast, in the control group, the majority of the fifth-year students $(60.46 \%)$ rate their behavior as approximately half in line with family values. It is obvious that in the multi-ethnic student community, this tendency was formed after the middle of the overall training in the university as the data for fourth-years are very similar (55.81\% of participants). However, at the beginning of the training, every fifth first-year student from the multi-ethnic group $(20.93 \%)$ claimed that they did not associate their behavior with traditional family values (Fig. 4).

Figures 5 and 6 describe the results of participants' assessment of the use of their native language to communicate with their relatives and conduct an internal monologue. Hence, none of the

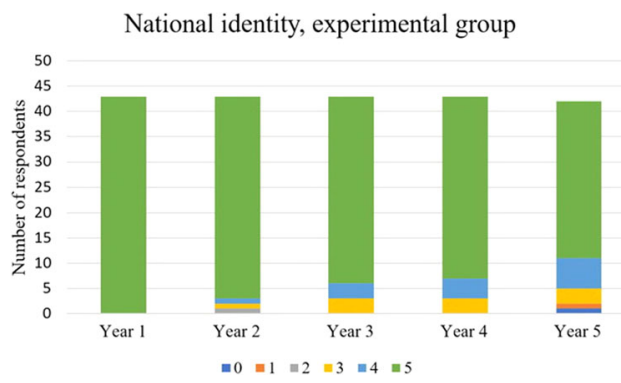

Fig. 1 Assessment of students' own national identity (experimental group). Number of respondents from the first- to fifth-year of study.

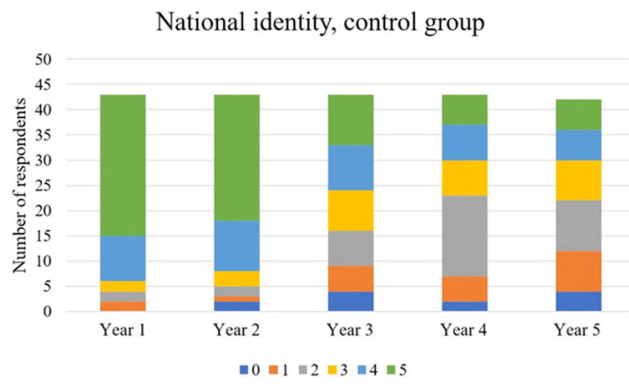

Fig. 2 Assessment of students' own national identity (control group). Number of respondents from the first- to fifth-year of study.

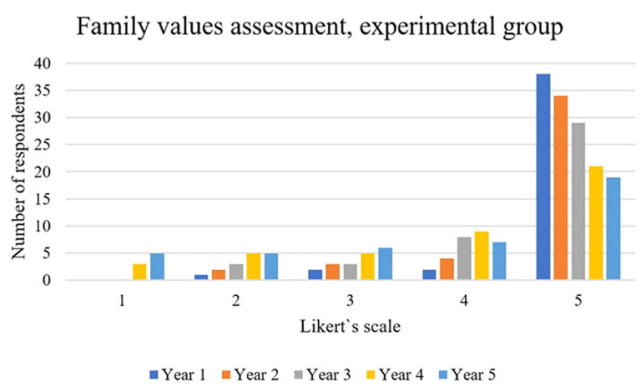

Fig. 3 Assessment of compliance with family values (experimental group). Number of respondents from the first- to fifth-year of study.

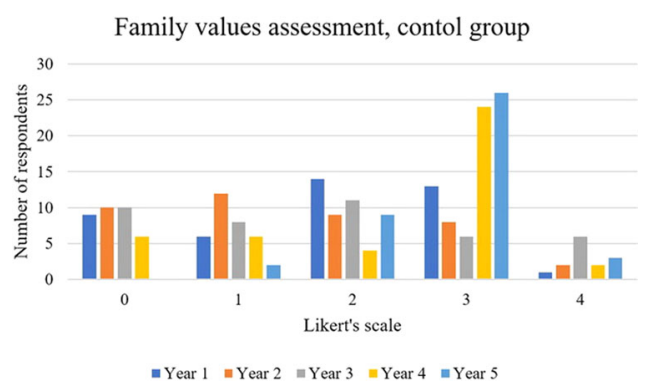

Fig. 4 Assessment of compliance with family values (control group). Number of respondents from the first- to fifth-year of study. 
Assessment of native language use, experimental group

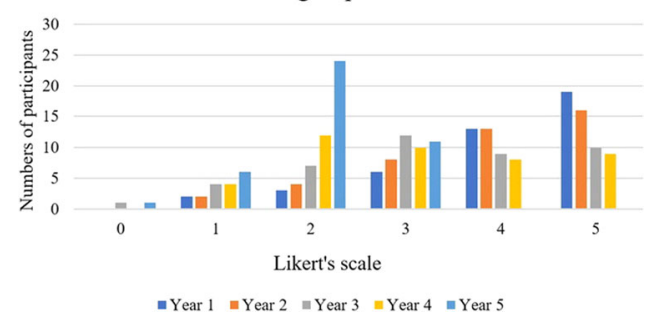

Fig. 5 Assessment of native language use (experimental group). Number of respondents from the first- to fifth-year of study.

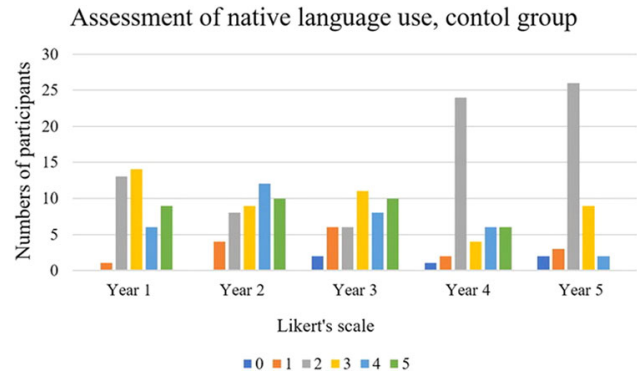

Fig. 6 Assessment of native language use (control group). Number of respondents from the first- to fifth-year of study.

fifth-year Daghestani students indicated that they constantly use their native language to talk to themselves, $57.14 \%$ turn to their native language in many cases, and $45.24 \%$ reported that they never use their native language in communication, even with themselves. Obviously, such a result might stem from a very strong impact of the constant foreign-language environment and the fact that Russian and English prevail in teaching, literature, and everyday communication.

In the control group, there was a minor change in the pattern of using the native language during the training. The most characteristic changes occurred during the last years of study when more than half of all students surveyed (61.9\% of the fifthyears and $55.81 \%$ of the fourth-years) asserted to use a foreign language in many cases. In general, the change in the control group is within the statistical error (except for two " 2 " scores on the Likert scale for the fourth- and fifth-years). Accordingly, it can be argued that, on average, the use of the native language in a multi-ethnic environment does not dramatically change in the case of the general sample evaluation but can show a striking difference when considering a particular ethnic group of students, for example, the Dagestanis.

When testing the hypotheses of the study, the control group value was taken as the critical value and was compared with the same value of the experimental group. The $\chi^{2}$ value exceeded the critical value only in a few cases:

1. the value of ethnic self-identification by language, adherence to family values, and personal national identity of the first- and third-year students is significantly higher than that of the experimental group ( $\chi^{2}$ values in the three tests did not exceed the critical value);

2 . in the experimental group, the $\chi^{2}$ value for females was consistently higher than that for males in the three tests;

3. there is an average correlation $(r=0.587)$ between both groups in the assessment of the use of the national language by fifth-years.
Based on these results, it is necessary to partially reject null hypothesis 1, assuming a statistically significant difference in the national identity of males and females in the experimental group. From this it follows that national identity in language and adherence to the family values and norms of behavior received in childhood are preserved by females to a greater extent and for a longer time. They also more often identify themselves as the representatives of the Dagestani ethnic group.

Null hypothesis 2 should also be partially rejected as there is a significant statistical difference between the data of the experimental and control groups for first-third-year students, which disappears in the fourth and fifth-years of study. Thus, it can be declared that Dagestani students retain the features and high assessment of their own national identity in all the parameters (language, adherence to family values, and personal identity) to a greater extent and over a more prolonged period. This indicates that the effect of family and traditional values learned in childhood is much stronger in the experimental group than that in control.

At the same time, the correlation between the assessment of the national language use for communication made by the control and the experimental groups and the apparent tendency towards identity blurring by the fifth-year observed in the three tests point to the strong and intense influence of the multi-ethnic environment. However, this correlation appeared only by the end of training and only in the context of language use. Hence, it can be concluded that it is the linguistic behavior of all ethnic identifiers that changes the fastest in a multi-ethnic environment.

In other respects, the Dagestanis retained their explicit adherence to national values and clear national identity. The revealed peculiarities in language use are mainly connected with the fact that communication, learning, and living take place in a foreign-language environment. In sum, the obtained findings suggest that ethnic identity is gradually blurred in a multiethnic student environment. What is more, the process of development of ethnic identity in different ethnic groups is obviously not homogeneous, as evidenced by the example of the Dagestanis.

\section{Discussion}

National identity determination is still a complex and highly subjective criterion for being assessed. In our study, we rely on subjective identification as the key indicator of a person's national identity. In most cases, the development of national identity in a family environment takes place automatically, but it can be significantly adjusted at a more mature age (Blake, 2019). A number of researchers point out that the correction of one's own awareness as a representative of a certain people may be changed towards the development of a neutral multi-ethnic consciousness in the event of further academic study and intensive selfeducation (Rath and Schutjens, 2019; Svensson et al., 2018; Thijs, 2017). The acquisition of a large amount of knowledge about other peoples, frequent communication, possible change in religious affiliation, as well as the assimilation of new sets of values can significantly level the value orientations acquired in childhood and adolescence. Simultaneously, a positive attitude towards one's ethnic group does not necessarily change. It often becomes even more consolidated despite the fact that self-identification with a certain group of people who share common behavior patterns, traits, and values may become weaker (JohnstonGuerrero, 2016). It is this process that was observed within the framework of the current study when the features of identity at the beginning of university studies blurred by the fifth-year of training. 
In many cases, the learning process is associated with the migration of students, which is one of the reasons for the need to go beyond traditional culture or socio-economic limitations (Riaño and Piguet, 2016). In such circumstances, ethnicity can be perceived as a negative deterrent and acquire negative connotations (Blake, 2019). This should be avoided through the creation of conditions for the development of the national characteristics of all peoples supported at the state level (Mustafaev et al., 2016b; Nikolaeva and Savvinov, 2016).

The need for additional gender research within the framework of this article was stimulated by the fact that studies on the dynamics of national identity in the student and school environment have recently been focused on the issue of women's selfidentification and their position in relation to traditional and family values (Harel-Shalev et al., 2020). Despite the fact that in most cultures retaining strong traditional behavior characteristics, resilience to change is obviously higher, in the last decade, women who represent these cultures have been increasingly demonstrating a higher willingness to break away from them in a multi-ethnic environment (Shakhbanova et al., 2018; Zaman, 2020). The limited set of female cultural and economic roles does not correspond to the needs of modern society and economy, and the availability of information and the formation of a common information space contributes to the spread of feminist ideas. Nevertheless, in our study, a more traditional identification of women in the Dagestan ethnic group was manifested. Other research works also point to a similar phenomenon emphasizing that the reason for this may be both the dominance of a certain type of thinking associated with neurophysiological mechanisms and the role of the woman as the guardian of traditional values, which increased the importance of women in traditional culture (Spees et al., 2017; Svensson et al., 2018). The preservance of this importance can push women towards the desire to identify themselves with family values more strongly (Harvey et al., 2017). On the other hand, such behavior may better meet the expectations of public opinion and act as a gesture of social mimicry (Verkuyten, 2018).

The results of the current investigation showed that language as a means of national identity loses its positions as an influencer and is primarily affected by acculturation processes (Arredondo et al., 2016). It was noted that in a multi-ethnic group of students, changes in the pattern of using their native language were minimal throughout the whole study period. The greatest changes, in turn, were recorded for students of the last two years of training when more than half of them relied upon a non-native language in the predominance of cases $(61.9 \%$ of the fifth-years and $55.81 \%$ of the fourth-years).

Self-identification with a certain group was the most stable of all the national identity parameters considered in this research. Studies conducted in other countries indicate that changes in language, behavior, economic activity, and other aspects of a person's life may have little effect on their national identity (Akhtarieva et al., 2019; Bamberger, 2020; Cho and Hwang, 2019). A departure from family values can occur naturally due to the change of place of residence and certain circumstances, but it has almost no effect on personal identity. Nevertheless, either externally imposed or self-adopted behavioral changes may well be combined with traditional norms learned from childhood. Therefore, the question of the close connection between the recognition of the importance of traditional family values as extremely significant and national identity remains open for researchers and requires further careful study.

\section{Conclusion}

The need to study the dynamic processes of national identity formation makes researchers consider students as a group where these processes are of particular importance and lead to the most dramatic changes. In the student environment, there is a collision of traditional family values, which in most cases represent ethnicity-driven characteristics of behavior and value orientations and the influence of a multi-cultural and multi-ethnic environment. The objective of the study was to determine the effect of family values on the national identity formation among Dagestani students, as well as to identify whether there are any significant statistical differences in these terms between males and females. The study involved two groups of first-fifth-year students (214 participants each) from 15 Moscow universities. Group 1 (experimental) included Dagestani students, and group 2 (control) consisted of randomly selected representatives of different ethnicities. The proportion of male and female respondents was equal. To study the national identity of students, assess the use of their native language as an ethnic identifier, as well as evaluate family values, all study participants were addressed specially developed survey. Its results across two groups were compared based on the outcomes of Pearson's chi-squared test and Pearson's correlation coefficient calculation. This enabled partial rejection of the study hypotheses claiming that there is no correlation between the ethnic identification of the experimental and control groups and that there are no significant differences between the ethnic identification indicators of different sexes. The reason for partial hypotheses rejection was that the collected findings demonstrated their acceptability for the fourth- and fifth-year students solely. Thus, it can be stated that ethnic identity formation is gradually blurred in a multi-ethnic student environment, and this process is not homogeneous in different ethnic groups.

\section{Data availability}

All data analyzed are contained in the paper.

Received: 22 April 2021; Accepted: 18 October 2021; Published online: 17 November 2021

\section{References}

Abdulmanapov P (2021) Assessment of the demographic policy effectiveness in the Republic of Dagestan. In: VIII International Scientific and Practical Conference' Current problems of social and labour relations' (ISPC-CPSLR 2020). Atlantis Press, pp. 14-18

Ahmad Y, Yusof NM (2017) Multi-ethnic school environment from the school leader's perspective: challenges and approaches to improve multi-cultural competency among teachers in Malaysia. As Ethn 18(3):296-309. https:// doi.org/10.1080/14631369.2016.1225257

Akhtarieva R, Ibragimova E, Tarasova A (2019) Dynamics of acculturation processes among foreign students in the multi-ethnic educational environment of the higher educational establishment. JSSER 10(3):82-102

Arredondo MM, Rosado M, Satterfield T (2016) Understanding the impact of heritage language on ethnic identity formation and literacy for US Latino children. J Cognit Cult 16(3-4):245-266. https://doi.org/10.1163/15685373-12342179

Bamberger A (2020) Accumulating cosmopolitan and ethnic identity capital through international student mobility. Stud High Educ 45(7):1367-1379. https://doi.org/10.1080/03075079.2019.1597037

Blake MK (2019) Self and group racial/ethnic identification among emerging adults. Emerg Adulthood 7(2):138-149.

Carment D, Jean LS, Prest S (2006) Sub-national Report for Dagestan: events, scenarios and analysis. country indicators for foreign policy project. The Norman Paterson School of International Affairs, Carleton University

Chikaeva KS, Belikova NY, Kasyanov VV et al. (2019) The traditional family: the institutional invariants of development on the South of Russia. Dilemas contemp Educ Polí Valores 6:1-19

Cho E, Hwang S (2019) Exploring changes in multi-ethnic students' mathematics achievement motivation: a longitudinal study using expectancy-value theory. Math Educ 58(1):101-120. https://doi.org/10.7468/mathedu.2019.58.1.101

Clark MA, Rudolph CW, Zhdanova L, Michel JS, Baltes BB(2017) Organizational support factors and work-family outcomes: exploring gender differences J Fam Issues 38(11):1520-1545. https://doi.org/10.1177/0192513X15585809 
Dobrushina N, Kultepina $\mathrm{O}(2021)$ The rise of a lingua franca: the case of Russian in Dagestan Int J Biling 25(1):338-358. https://doi.org/10.1177/ 1367006920959717

Fischer JL, Zvonkovic A, Juergens C, Engler R, Frederick H(2015) Work, family, and well-being at midlife: a person-centered approach $\mathrm{J}$ Fam Issues 36(1):56-86. https://doi.org/10.1177/0192513X13488370

Fisher S, Zapolski TCB, Sheehan C, Barnes-Najor J(2017) Pathway of protection: ethnic identity, self-esteem, and substance use among multiracial youth Addict Behav 72:27-32. https://doi.org/10.1016/j.addbeh.2017.03.003

Forrest-Bank SS, Cuellar MJ(2018) The mediating effects of ethnic identity on the relationships between racial microaggression and psychological well-being Soc Work Res 42(1):44-56. https://doi.org/10.1093/swr/svx023

Gummadam P, Pittman LD, Ioffe M (2016) School belonging, ethnic identity, and psychological adjustment among ethnic minority college students. J Exp Educ 84(2):289-306. https://doi.org/10.1080/00220973.2015.1048844

Harel-Shalev A, Kook R, Elkrenawe F (2020) Changing gender roles within conservative communities: an analysis of group interview narratives of Bedouin women. Soc Polit Int Stud Gender State Soc 27(3):486-509. https://doi.org/ $10.1093 / \mathrm{sp} / \mathrm{jxaa} 013$

Harvey HL, Parahoo S, Santally M (2017) Should gender differences be considered when assessing student satisfaction in the online learning environment for millennials? High Educ Q 71(2):141-158. https://doi.org/10.1111/hequ.12116

Johnston-Guerrero MP (2016) Embracing the messiness: Critical and diverse perspectives on racial and ethnic identity development. New Dir Stud Serv 154(2016):43-55

Kamalova T, Shabanova M, Umavov Y, Napisat G (2021) Developing a model for managing the quality of education in the Republic of Dagestan. In: VIII International Scientific and Practical Conference'Current problems of social and labour relations' (ISPC-CPSLR 2020). Atlantis Press, pp. 306-310

Kaya M, Halford WK, Hiew DN, Sheffield J, Van De Vijver FJ (2019) Ethnic identification and relationship satisfaction in Chinese, Western, and intercultural Chinese-Western couples. Couple Family Psychol 8(3):121. https:// doi.org/10.1037/cfp0000120

Kusumaningtyas N, Atmaja HT, Subagyo S (2019) The Role of social media, family and school in building Indonesian values to multi-ethnic students at SMP Negeri 2 Pekalongan. J Soc Stud Educ Res 8(1):19-26

Maximova OA, Belyaev VA (2017) Generational indigenation in a multi-ethnic and multi-religious society (Tatarstan, Russia). Opción Rev de Cienc Hum Soc 84:38-64

Mustafaev M, Mustafaeva M, Magomedova Z (2016a) Formation and development of patriotism as the most important stability factor of modern Dagestan society. Sci Alm Black Sea Reg Countries 3(7):26-30

Mustafaeva M, Mustafaev F, Mustafaev M (2016b) Comparative analysis of modern Dagestan student youth value orientations. Sci Alm Black Sea Reg Countries 4(8):69-73

Nikolaeva AD, Savvinov VM (2016) Multi-ethnic school in the Russian federation: the preconditions of formation and development (a case study of a national region). Int Electron J Math Educ 11(10):3405-3414

Poster WR (2002) Racialism, sexuality, and masculinity: gendering 'global ethnography' of the workplace. Soc Pol Int Stud Gender State Soc 9(1):126-158. https://doi.org/10.1093/sp/9.1.126

Rath J, Schutjens V (2019) Advancing the frontiers in ethnic entrepreneurship studies. Tijdschr Econ Soc Geogr 110(5):579-587. https://doi.org/10.1111/ tesg. 12398

Riaño Y, Piguet E (2016) International student migration. In: Oxford Bibliographies. Oxford University Press, Oxford, pp. 1-24

Shakhbanova MM, Gafiatulina NK, Samygin SI et al. (2018) Youth of the South of Russia: Specifics of manifestation of ethnic identity (on the example of the Dagestan republic). Int J Pure Appl Math 118(24):1-15

Spees L, Perreira KM, Fuligni A (2017) Family matters: promoting the academic adaptation of Latino youth in new and established destination. J Fam Issues 38(4):457-479.
Svensson Y, Berne J, Syed M (2018) A narrative approach to the role of others in ethnic identity formation. Cult Divers Ethn Minor Psychol 24(2):187-195. https://doi.org/10.1037/cdp0000182

Thijs J (2017) Student-Teacher Relationships and Interethnic Relations. In: Rutland A, Nesdale D, Spears Brown C (eds) The Wiley Handbook of group processes in children and adolescents. John Wiley \& Sons, Hoboken, NJ, pp. 416-434

Thomsen JPF, Rafiqi A (2017) The contact-prejudice relationship among ethnic minorities: examining the facilitative influence of religiosity. Soc Sci Q 98(5):1571-1586. https://doi.org/10.1111/ssqu.12368

van der Does T, Adem M (2019) Gendered paths in ethnic identity exploration between adolescence and emerging adulthood. Emerg Adulthood 7(2):109-118. https://doi.org/10.1177/2167696818793809

Verkuyten M (2018) The social psychology of ethnic identity. Routledge, Abington Zagirova EM, Shikhaliyeva DS, Murtuzova ZM, et al (2018) Reproductive installations of Dagestan peoples. Turk Online J Design Art Com 8(SMRCHSPCL):543-548

Zaman MF (2020) The problem of the rebellious religious women: Pakistan, gender, and the Islamic revival. Soc Pol Int Stud Gender State Soc 27(2):212-233. https://doi.org/10.1093/sp/jxz001

Zimmermann L, Zimmermann KF, Constant A (2007) Ethnic self-identification of first-generation immigrants. Int Migr Rev 41(3):769-781. https://doi.org/ 10.1111/j.1747-7379.2007.00093.x

\section{Competing interests}

The author declares no competing interests.

\section{Ethical approval}

Compliance with ethical requirements was approved by the Institutional Review Board of Peoples Friendship University of Russia by protocol No. 3248 dated 07.24.2020.

\section{Informed consent}

All participants gave their written informed consent. All participants were guaranteed the anonymity of their participation in the survey. No personal data were processed or collected in the course of the study.

\section{Additional information}

Correspondence and requests for materials should be addressed to Saida Gasanova.

Reprints and permission information is available at http://www.nature.com/reprints

Publisher's note Springer Nature remains neutral with regard to jurisdictional claims in published maps and institutional affiliations.

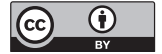

Open Access This article is licensed under a Creative Commons Attribution 4.0 International License, which permits use, sharing, adaptation, distribution and reproduction in any medium or format, as long as you give appropriate credit to the original author(s) and the source, provide a link to the Creative Commons license, and indicate if changes were made. The images or other third party material in this article are included in the article's Creative Commons license, unles indicated otherwise in a credit line to the material. If material is not included in the article's Creative Commons license and your intended use is not permitted by statutory regulation or exceeds the permitted use, you will need to obtain permission directly from the copyright holder. To view a copy of this license, visit http://creativecommons.org/ licenses/by/4.0/.

(C) The Author(s) 2021 